\title{
Cyanotic congenital heart disease: Impact on growth and endocrine functions.
}

1. FCPS (Paeds Cardiology) Head Paediatric Cardiology

The Children's Hospital \&

The Institute of Child Health Multan.

2. MBBS, DCH, FCPS

Associate Professor Pediatric Endocrinology

The Children's Hospital \&

The Institute of Child Health Multan.

3. FCPS (Paeds Medicine)

Senior Registrar Paeds Cardiology

The Children's Hospital \&

The Institute of Child Health Multan.

4. FCPS (Paeds Medicne)

Fellow in Paediatric Cardiology

The Children's Hospital \&

The Institute of Child Health Multan.

5. FCPS (Paeds Medicine)

Senior Registrar Pediatric

Cardiology

The Children's Hospital \&

The Institute of Child Health Multan.

Correspondence Address:

Dr. Hafiz Muhammad Anwar-ul-Haq

Department of Paediatric Cardiology

The Children's Hospital \&

The Institute of Child Health Multan.

dr.anwaarulhaq@yahoo.com

Article received on:

07/07/2020

Accepted for publication:

08/09/2020

\section{INTRODUCTION}

Congenital heart disease (CHD) is known to be structural abnormalities related to the heart or intrathoracic great vessels taking place while fetus is developing. ${ }^{1}$ CHD is recorded to be the commonest form of birth defect affecting 8-9 per 1000 live births and is described as the most frequent cause of mortality among children having congenital malformations. ${ }^{2} \mathrm{CHD}$ can be classified as either non-cyanotic CHD or cyanotic $\mathrm{CHD}$ (CCHD). CCHD is further divided in to three different forms of lesions like right heart obstructive lesions, left heart obstructive lesions or mixing lesions. ${ }^{3,4}$ Among CHD cases, around $25 \%$ are estimated to be CCHD cases. $^{2}$ Tetralogy of Fallot (TOF) and transposition of the great arteries (TGA) are noted to be the commonest forms of CCHD. ${ }^{5}$ TGA is also known to be the commonest CCHD manifestation found in the $1^{\text {st }}$ week following birth. In cases having congenital malformations, $35 \%$ of the deaths among infants are noted due to cardiovascular abnormalities. ${ }^{2}$

In infants having CCHD, $15-20 \%$ of the cases are due to known chromosomal abnormalities while majority of them are aneuploidies like trisomy 21, 13, 18 and Turner syndrome. ${ }^{2}$ Environmental factors include maternal illness like diabetes mellitus or phenylketonuria. Maternal exposure to toxins, drugs or viral infections during pregnancy also contribute to CHD in the fetus.

As CCHDs are models of chronic hypoxia, these are known to impact endocrine system. ${ }^{6,7}$ 
Effect of CCHDs on growth has been studied sparingly in the past. A study conducted by Eren $\mathrm{E}$ et al from Turkey ${ }^{8}$ evaluating endocrine functions among children with CCHD found that chronic hypoxia proved to have a negative effect on nutritional and growth parameters. Serum glucose was significantly decreased $(75+15 \mathrm{mg} /$ dl vs $83+12$ ) among cases in comparison to controls $(p=0.033)$. Significantly low scores of height and weight among children with CCHD in comparison to controls were also reported in that same Turkish study. ${ }^{8}$ Growth retardation (GR) is a common and serious complication in children with CCHD. Underlying causes of GR among cases of CCHD is not fully understood. Chen CW and coworkers noted delayed growth as well as development in children having CCHD in comparison to normal children..$^{9,10}$

Not many studies have been conducted around the world to find out the impact of $\mathrm{CCHD}$ on growth and endocrine functions of the affected children. No work is found from Pakistan regarding these aspects. This study was planned to find out the impact of CCHD on growth and endocrine functions at a tertiary care child healthcare facility of South Punjab. Results of this study are thought to shed light on the extent of CCHD affecting individuals in terms of growth and normal endocrine functions.

\section{MATERIAL \& METHODS}

This case control study was done at the Department of Pediatric Cardiology and Department of Pediatric Endocrinology of The Children's Hospital and The Institute of Child's Health $(\mathrm{ICH})$, Multan, Pakistan from December 2018 to March 2020. Approval from the Institutional Ethical Committee was taken for this research (09/18/Ethical committee/CH\&ICH). Informed consent was also sought from parents/guardians of all the study participants, either having $\mathrm{CCHD}$ or controls.

A sample size of a total of 92 cases (including 46 cases and 46 controls) was calculated considering 95\% confidence interval (2-sided), with power of $80 \%$ and ratio of sample size (group 2/group 1) as 1 and $\mathrm{P} 1=75+15$ and
$\mathrm{P} 2=83+12 .^{8}$ During the study period, a total of 53 cases of Echocardiography confirmed CCHD were registered. Along with 53 cases, 50 controls during the study period were also enrolled. All cases were non operated children having age more than 5 years and presenting to cardiology outpatient department of The Children's Hospital and $\mathrm{ICH}$, Multan. All post-operative cases who underwent cardiac surgery for CCHDs either palliative or corrective or patients having associated chromosomal disorders or syndromes were excluded. Patients having any other chronic systemic ailments, renal or hepatic failure, additional genetic or endocrinological abnormalities like congenital hypothyroidism, were also not enrolled. Controls were consisted of patients aged more than 5 years, presented to pediatric medicine outpatient department of The Children's Hospital \& ICH with complaints like headache, abdominal discomfort or routine vaccination visits.

Height, weight and body mass index (BMI) were noted among all study participants. Complete blood count, serum sodium (Na), potassium $(\mathrm{K})$, calcium $(\mathrm{Ca})$, phosphorus $(\mathrm{P})$, alkaline phosphatase (ALP), urea, creatinine and phosphorus were measured using the blood samples drawn. Fasting glucose and insulin level were also assessed for carbohydrate metabolism. $\mathrm{ACTH}$, cortisol for adrenal examination, TSH, T4 (fT4) for thyroid functions, and parathormone (PTH) level along with Vitamin D level for bone metabolism were assessed.

The statistical analysis was performed using SPSS 20.0. For qualitative variables, frequency and percentages were calculated. The Student's t-test was performed to compare the continuous variables while chi square test was applied to compare qualitative variables. $\mathrm{P}$ value of less than 0.05 was considered significant.

\section{RESULTS}

Among 53 cases, there were 30 (56.6\%) boys and $23(43.4 \%)$ girls while among 50 controls, $30(60.0 \%)$ boys and $20(40.0 \%)$ girls ( $p$ value $=0.7268$ ). Mean age among cases was noted to be $4.62 \pm 3.27$ years while among controls, it 
was $4.28 \pm 3.74$ years $(p$ value $=0.6239)$.

Table-I showing that the most common diagnosis of CCHD among cases, 24 (45.3\%) were TOF followed by 9 (17.0\%) TGA with VSD with PS and 4 (7.5\%) PA.

Table-Il highlights that there was no significant difference between cases and controls in terms of Height or BMI ( $p$ value $>0.05$ ) whereas mean weight of cases was significantly lower in comparison to controls $(21.19+6.24 \mathrm{~kg}$ vs. $26.48+8.1 \mathrm{~kg}, \mathrm{p}$ value $=0.0003)$.

Table-III showing comparison of various biochemical laboratory findings among cases and controls. Blood glucose was significantly lower among cases in comparison to controls $(77.58+14.58 \mathrm{mg} / \mathrm{dl}$ vs. $87.25+11.82 \mathrm{mg} /$ $\mathrm{dl}$, $\mathrm{p}$ value $=0.0004$ ) whereas uric acid was significantly raised among cases in comparison to controls $(5.08+2.31 \mathrm{mg} / \mathrm{dl}$ vs. $3.62+0.67 \mathrm{mg} /$ $\mathrm{dl}, \mathrm{p}$ value $<0.0001)$ while all other biochemical laboratory findings were statistically similar between cases and controls ( $p$ value $>0.05$ ).

Table-IV compares findings of various hormone levels between cases and controls. No significant difference was found in between cases and controls in terms of various hormone levels studied in the present research ( $p$ value $>0.05$ ) except IGF-1 (ng/ml) levels that were significantly decreased among cases in comparison to controls ( $p$ value $<0.0001$ ).

\begin{tabular}{|l|c|}
\hline \multicolumn{1}{|c|}{ Diagnosis } & Number of Patients (\%) \\
\hline Tetralogy of Fallot (TOF) & $24(45.3 \%)$ \\
\hline TGA with Ventricular Septal Defect (VSD) with Pulmonary Stenosis (PS) & $9(17.0 \%)$ \\
\hline Pulmonary Atresia & $4(7.5 \%)$ \\
\hline Tricuspid Atresia & $3(5.7 \%)$ \\
\hline Univentricular Heart with PS & $2(3.8 \%)$ \\
\hline Complete Atrioventricular Septal Defect (AVSD) with PS & $1(1.9 \%)$ \\
\hline Complex Congenital Heart Disease & $8(15.1 \%)$ \\
\hline Ebstein Anomaly & $2(3.8 \%)$ \\
\hline
\end{tabular}

Table-I. Diagnostic findings among cases $(n=53)$

\begin{tabular}{|c|c|c|c|}
\hline \multirow{2}{*}{ Characteristics } & \multicolumn{2}{|c|}{ Mean + Standard Deviations } & \multirow{2}{*}{ P-Value } \\
\hline & Cases $(n=53)$ & Controls $(n=50)$ & \\
\hline Height (cm) & $107.20+42.57$ & $118.83+52.29$ & 0.2175 \\
\hline Weight (kg) & $21.19+6.24$ & $26.48+8.1$ & 0.0003 \\
\hline BMI & $16.85+2.47$ & $17.35+2.61$ & 0.3202 \\
\hline \multicolumn{4}{|c|}{ Table-II. Characteristics of cases and controls } \\
\hline \multirow{2}{*}{ Biochemical Findings } & \multicolumn{2}{|c|}{ Mean + Standard Deviations } & \multirow{2}{*}{ P-Value } \\
\hline & Cases $(n=53)$ & Controls $(n=50)$ & \\
\hline Blood Glucose (mg/dl) & $77.58+14.58$ & $87.25+11.82$ & 0.0004 \\
\hline Urea (mg/dl) & $20.15+6.75$ & $22.07+6.82$ & 0.1542 \\
\hline Creatinine (mg/dl) & $0.62+0.10$ & $0.57+0.80$ & 0.6527 \\
\hline Uric Acid (mg/dl) & $5.08+2.31$ & $3.62+0.67$ & $<0.0001$ \\
\hline Alkaline Phosphatase (U/L) & $242.74+80.81$ & $214.14+71.54$ & 0.0606 \\
\hline Sodium (mEq/L) & $135.26+2.0$ & $136.17+1.8$ & 0.8112 \\
\hline Potassium (mEq/L) & $4.48+0.62$ & $4.42+0.58$ & 0.6136 \\
\hline Calcium (mg/dl) & $9.30+0.52$ & $9.49+0.35$ & 0.1142 \\
\hline Phosphorus (mg/dl) & $5.3+1.1$ & $5.0+0.8$ & 0.1184 \\
\hline
\end{tabular}

Table-III. Biochemical laboratory findings among cases and controls 


\begin{tabular}{|l|c|c|c|}
\hline \multicolumn{1}{|c|}{ Hormone Levels } & \multicolumn{2}{c|}{ Mean + Standard Deviations } & P-Value \\
\cline { 2 - 4 } & Cases $(\mathbf{n = 5 3 )}$ & Controls $(\mathbf{n = 5 0})$ & 0.0718 \\
\hline Free T4 $(\mathrm{ng} / \mathrm{dl})$ & $1.32+0.18$ & $1.25+0.21$ & 0.0610 \\
\hline TSH $(\mathrm{mlU} / \mathrm{ml})$ & $2.6224+0.782$ & $2.2928+0.978$ & 0.2144 \\
\hline Adrenocorticotropic Hormone $(\mathrm{pg} / \mathrm{ml})$ & $18.53+12.61$ & $21.92+14.89$ & $<0.0001$ \\
\hline IGF-1 $(\mathrm{ng} / \mathrm{ml})$ & $84.6+74.8$ & $198.2+135.4$ & 0.0595 \\
\hline Cortisol $(\mathrm{mcg} / \mathrm{dl})$ & $12.24+6.6$ & $10.0+5.2$ & 0.8257 \\
\hline Insulin $(\mathrm{mU} / \mathrm{ml})$ & $8.17+9.93$ & $8.52+8.84$ & 0.0612 \\
\hline Vitamin D $(\mathrm{ng} / \mathrm{L})$ & $30.82+17.62$ & $23.61+20.92$ & \\
\hline Parathyroid Hormone $(\mathrm{pg} / \mathrm{ml})$ & $74.35+68.52$ & $56.37+26.47$ & 0.0855 \\
\hline
\end{tabular}

Table-IV. Findings of hormone levels among cases and controls

\section{DISCUSSION}

GR (Growth Retardation) is considered an important issue among children having CHD. It has also been highlighted by the previous researchers that children having $\mathrm{CCHD}$ have more pronounced growth impairment. ${ }^{11,12}$

In the current study, although, mean height of cases in comparison to controls was much lesser $(107.20+42.57 \mathrm{~cm}$ vs. $118.83+52.29 \mathrm{~cm})$ but it did not reach statistical significance ( $p$ value $=0.2175$ ). It was also observed that mean weight of cases was significantly lower in comparison to controls $(21.19+6.24 \mathrm{~kg}$ vs. $26.48+8.1 \mathrm{~kg}, \mathrm{p}$ value $=0.0003$ ). Hansen $\mathrm{SR}$ and Dorup I noted that incidence of GR was much higher among cases having CCHD while it hampered both weight and height. ${ }^{13}$ In another study, it was found that heights of $55 \%$ of the cases having CCHD, weights of more than half of the study participants was $<3$ percentiles which is again correlating well with current findings where difference of weight among cases and controls reached statistical significance. ${ }^{14} \mathrm{~A}$ study from Turkey recorded weight, height, and both weight and height to be $<3$ percentiles among $20 \%, 13.3 \%$ and $13.3 \%$ CCHD cases respectively. ${ }^{8}$ Lower levels of $\mathrm{BMI}$ among cases in the present study are also highlighting nutritional growth impairments. Children having CCHD are also found to have lower weight, BMI and head circumference when compared to children having acyanotic $\mathrm{CHD} .^{5}$

We have noted that there was no significant difference in levels of various hormones studied between cases and controls. Researchers also noted that hormone levels of children having CCHD were similar to controls but they found that levels of IGF-1 and IGF binding protein 3 (IGFBP3) were significantly lower among cases in comparison to controls. ${ }^{8}$ Lower levels of IGF1 found in our study and by other researchers among CCHD cases might be due to the inhibition of binding of growth hormone to its receptor during chronic hypoxia. Post-operative cases of CCHD when compared to pre-operative status have been found to have higher BMI so higher levels of IGF-1. 15

It is widely accepted that hypoxia is known to have an effect on adrenal cortex and plays an important role during adrenal-steroid synthesis. ${ }^{8,16}$ Roles of acute and chronic hypoxia on the anteriorhypothalamus and adrenal cortex have been studied among rats and rabbits and it has been found that ACTH and CAMP secretions are higher because of acute hypoxia. ${ }^{17,18}$ Although, we did not find significant difference in terms of ACTH or cortisol levels between cases and controls but lower levels of ACTH along with normal levels of cortisol among $7 \mathrm{CCHD}$ cases in the present study might be elaborated with the help of central ACTH inhibitor under stress. Similar findings have been reported by other researchers as well, showing increased disease severity among CCHD cases. ${ }^{8}$

Systemic hypoxia is known to be linked with insulin resistance. Cases having sleep apnea are noted to have much higher insulin resistance due to intermittent hypoxia. ${ }^{19}$ Although there was no significant difference between insulin 
levels among cases and controls in the present study, but lower levels of plasma insulin were found among CCHD cases in the present study which could be because of impaired insulin secretions. CCHD cases are also more prone to have hypoglycemia so a special attention should be given to these cases in the post-operative period. ${ }^{20}$ In the present study, significantly lower levels of glucose were recorded among CCHD cases in comparison to controls. These findings have been observed by other researchers as well. Lower glucose levels could be due to increased demand of energy for circulation and respiration among CCHD individuals. Higher levels of insulin resistance can also be explained as preventable mechanism against hypoglycemia. Our findings in terms of $\mathrm{fT} 4$ and TSH levels were quite similar to previous ones, showing no significant difference between cases and controls. ${ }^{21}$ This could also mean that pituitary-thyroid axis was intact and working normally. Pubertal delays are also suspected in patients with CCHD. ${ }^{22}$ Further studies in older age group survivors may be planned to elaborate this aspect.

In the present study uric acid was significantly raised among cases in comparison to controls $(5.08+2.31 \mathrm{mg} / \mathrm{dl}$ vs. $3.62+0.67 \mathrm{mg} / \mathrm{dl}, \mathrm{p}$ value $<0.0001)$. The exact mechanism behind this phenomenon is not known but pediatric age groups with CCHD have been pointed out to have higher risk of kidney injury in the past. ${ }^{23,24}$

There were few limitations to our study as well. As this was a single center study, in future, studies involving multi-centers and larger sample size will serve better. As we had only included children in preoperative status, future studies following children after corrective post-operative status for CCHD will give us insight about their endocrine functions as well.

\section{CONCLUSION}

Children with cyanotic congenital heart disease seem to have negative effects on nutrition and growth. Change in pituitary-adrenal axis is suspected while pituitary-thyroid axis seemed to be working fine among CCHD cases. Serum glucose and IGF-1 levels were significantly decreased among CCHD cases. Better nutritional support and early corrective surgery can possibly avoid growth delay in these children. In third world countries like Pakistan, where the nutritional status of even otherwise healthy children is not up to the mark and such patients with CCHD are at greater risk for nutritional deficiencies. Moreover, delay in diagnosis and then delay in surgical corrective treatment of CCHD is another major problem.

\section{ACKNOWLEDGEMENT}

The authors would like to thank Muhammad Aamir (Research Consultant, Bahawalpur) for his volunteer support in statistical analysis of this research.

\section{Copyright $(08$ Sep, 2020.}

\section{REFERENCES}

1. Rohit M, Rajan P. Approach to cyanotic congenital heart disease in children. Indian J Pediatr 2020; 87:372-80.

2. Ossa Galvis MM, Bhakta RT, Tarmahomed A, Mendez MD. Cyanotic heart disease. [Updated 2020 May 27]. In: StatPearls [Internet]. Treasure Island (FL): StatPearls Publishing; 2020.

3. Desai K, Rabinowitz EJ, Epstein S. Physiologic diagnosis of congenital heart disease in cyanotic neonates. Curr. Opin. Pediatr. 2019; 31(2):274-283.

4. Segura T, Gatzoulis MA. Where are we with coronary artery disease for the cyanotic patient with congenital heart disease? Int. J. Cardiol. 2019; 277:108-109.

5. Ulfah DA, Lestari ED, Salimo H, Lilijanti S, Artiko B. The effect of cyanotic and acyanotic congenital heart disease on children's growth velocity. Paediatr Indones. 2017; 57(3):159-62.

6. Noble K, Forsey J. An analysis of growth failure in children with congenital heart disease. Welsh Paediatr J. 2010; 32:13-6.

7. Mehrizi A, Drash A. Growth disturbance in congenital heart disease. J Pediatr. 1962; 61:418-29.

8. Eren E, Cakir ED, Bostan O, Saglam H, Tarim O. Evaluation of the endocrine functions in pediatric patients with cyanotic congenital heart disease. Biomed Res. 2013; 24(2):211-5.

9. Mohammad NB, Samuel BP, Vettukattil JJ. Subclinical atherosclerosis in patients with cyanotic congenital heart disease. Int. J. Cardiol. 2019; 282:44. 
10. Cameron JW, Rosenthal A, Olson AD. Malnutrition in hospitalized children with congenital heart disease. Arch Pediatr Adolesc Med 1995; 149:1098-1102.

11. Lijuan L, Kuanrong L, Caixia A, Jiajie F, Changying G, Suixin $L$, et al. Identification of risk factors affecting catch-up growth after infant congenital heart disease surgery: Rationale and design of a multicentre prospective cohort study in China. BMJ Open. 2019; 9(8):e030084.

12. Indramohan G, Pedigo TP, Rostoker N, Cambare M, Grogan T, Federman MD. Identification of risk factors for poor feeding in infants with congenital heart disease and a novel approach to improve oral feeding. J Pediatr Nurs 2017; 35:149-54.

13. Hansen, SR, Dorup I. Energy and nutrient intakes in congenital heart disease. Acta Paediatr. 1993; 82:16672.

14. Dundar B, Akcoral A, Saylam G, Unal N, Mese T, Hudaoglu S. et al. Chronic hypoxemia leads to reduced serum IGF-I levels in cyanotic congenital heart disease. J Pediatr Endocrinol Metab 2000; 13:431-6.

15. Steinbrech DS, Mehrara BJ, Saadeh PB, Chin G, Dudziak ME, Gerrets RP, et al. Hypoxia regulates VEGF expression and cellular proliferation by osteoblasts in vitro. Plast Reconstr Surg 1999; 104:738-47.

16. Rao PS. Management of congenital heart disease: State of the Art-Part II-Cyanotic heart defects. Children (Basel). 2019; 6(4):54.

17. Ducsay CA, Mlynarczyk M, Kaushal KM, Hyatt K, Hanson K, Myers DA. Long-term hypoxia enhances ACTH response to arginine vasopressin but not corticotropin-releasing hormone in the near-term ovine fetus. Am J Physiol Regul Integr Comp Physiol. 2009; 297: R892-9.
18. Ducsay CA, Hyatt K, Mlynarczyk M, Root BK, Kaushal $\mathrm{KM}$, Myers DA. Long-term hypoxia modulates expression of key genes regulating adrenomedullary function in the late gestation ovine fetus. Am J Physiol Regul Integr Comp Physiol. 2007; 293: R1997-2005.

19. Punjabi NM, Sorkin JD, Katzel LI, Goldberg AP, Schwartz AR, Smith PL. Sleep-disordered breathing and insulin resistance in middleaged and overweight men. Am J Respir Crit Care Med 2002; 165:677-82.

20. Salinas CE, Villena M, Blanco CE, Giussani DA. Adrenocortical suppression in highland chick embryos is restored during incubation at sea level. High Alt Med Biol 2011; 12:79-87.

21. Semple PD, Semple CG, Beastall GH, Brown TM, Watson WS, Hume R. Endocrine studies in cyanotic congenital heart disease. Scott Med J 1985; 30:25-9.

22. Menon SC, Al-Dulaimi R, McCrindle BW, Goldberg DJ, Sachdeva R, Goldstein $\mathrm{BH}$, et al. Delayed puberty and abnormal anthropometry and its associations with quality of life in young Fontan survivors: A multicenter cross-sectional study. Congenit Heart Dis. 2018; 13(3):463-469.

23. Pinar A, Murat D, Figen O, Esra B, Suna T, Derya A, et al. Effect of congenital heart disease on renal function in childhood. Nephron. Physiology. 2005; 99:10-15.

24. Amoozgar $\mathrm{H}$, Basiratnia M, Ghasemi F. Renal function in children with cyanotic congenital heart disease: Pre- and post-cardiac surgery evaluation. Iranian Journal of Pediatrics. 2014; 24(1):81-86. 


\begin{tabular}{|c|l|l|l|}
\hline \multicolumn{3}{|c}{ AUTHORSHIP AND CONTRIBUTION DECLARATION } \\
\hline Sr. \# & \multicolumn{1}{|c|}{ Author(s) Full Name } & \multicolumn{1}{|c|}{ Contribution to the paper } & Author(s) Signature \\
\hline 1 & M. Sohail Arshad & $\begin{array}{l}\text { Study concept, Supervision, } \\
\text { Responsible for Data's Integrity. } \\
\text { Data Analysis, Proof reading. }\end{array}$ \\
\hline 3 & Waqas Imran Khan & Arif Zulqarnain & Methodology, Discussion. \\
\hline 5 & Hafiz M. Anwar-ul-Haq & Data collection, Drafting. \\
\hline 5
\end{tabular}

